\title{
Advances and challenges on the in vitro production of secondary metabolites from medicinal plants
}

\author{
Jean Carlos Cardoso ${ }^{1} \mathbb{D}$; Maria Eduarda BS de Oliveira ${ }^{1} \mathbb{D}$; Fernanda de CI Cardoso ${ }^{1} \mathbb{D}$
}

${ }^{1}$ Universidade Federal de São Carlos (UFSCar), Araras-SP, Brazil; jeancardoso@ufscar.br (corresponding author)

\begin{abstract}
The production of secondary metabolites from medicinal plants, also called Plant-Derived Medicinal Compounds (PDMC), is gaining ground in the last decade. Concomitant to the increase in the knowledge about pharmacological properties of these compounds, horticultural plants are becoming the most important, sustainable and low-cost biomass source to obtain high-complex PDMCs to be used as medicaments. Biotechnological tools, including plant cell and tissue culture and plant genetic transformation, are increasingly being employed to produce high quality and rare PDMC under in vitro conditions. The proper use of these technologies requires studies in organogenesis to allow for better control of in vitro plant development and, thus, to the production of specific tissues and activation of biochemical routes that result in the biosynthesis of the target PDMCs. Either biotic or abiotic factors, called elicitors, are responsible for triggering the PDMC synthesis. In vitro techniques, when compared to the conventional cultivation of medicinal plants in greenhouse or in the field, have the advantages of (1) producing PDMCs in sterile and controlled environmental conditions, allowing better control of the developmental processes, such as organogenesis, and (2) producing tissues with high PDMC contents, due to the efficient use of different biotic and abiotic elicitors. Nevertheless, the process has many challenges, e.g., the establishment of stepby-step protocols for in vitro biomass and PDMC production, both involving and being affected by many factors. Other limitations are the high costs in opposition to the relatively cheaper alternative of growing medicinal plants conventionally. This paper aims to quickly review the general origin of plant secondary metabolites, the leading techniques and recent advances for PDMC in vitro production, and the challenges around the use of this promising technology.
\end{abstract}

Keywords: plant-derived medicinal compounds, in vitro cell and tissue culture, techniques, biotic and abiotic factors, biofactories.

\section{RESUMO}

Avanços e desafios na produção in vitro de metabólitos secundários de plantas medicinais

A produção de metabólitos secundários de plantas medicinais, também chamados de Compostos Medicinais Derivados de Plantas (PDMC), vem ganhando importância na última década. Concomitante ao aumento do conhecimento sobre as propriedades farmacológicas destes compostos, as plantas da horticultura tornam-se a fonte de biomassa mais importante, sustentável e de baixo custo para a obtenção de PDMCs de alta complexidade a serem utilizados como medicamentos. Ferramentas biotecnológicas, incluindo cultura de células e tecidos e transformação genética, estão sendo cada vez mais empregadas para produzir PDMCs raros e de alta qualidade sob condições in vitro. $\mathrm{O}$ uso adequado dessas tecnologias requer estudos em organogênese para permitir melhor controle do desenvolvimento in vitro das plantas e, assim, da produção de tecidos específicos e ativação das rotas bioquímicas que resultam na biossíntese dos PDMCs alvo. Elicitores bióticos ou abióticos são responsáveis por desencadear a síntese desses PDMCs. As técnicas de produção in vitro, quando comparadas ao cultivo convencional de plantas medicinais em casa de vegetação ou no campo, têm as vantagens de (1) produzir PDMCs em condições ambientais estéreis e controladas, permitindo um melhor controle de processos de desenvolvimento, como a organogênese, e (2) produzir tecidos com alto teor de PDMCs, devido à aplicação eficiente de diferentes elicitores. No entanto, o processo tem muitos desafios como, por exemplo, o estabelecimento de protocolos para produção in vitro de biomassa e PDMC, ambos envolvendo e sendo afetados por muitos fatores. Outras limitações são os altos custos em oposição à alternativa relativamente mais barata de cultivar plantas medicinais convencionalmente. $\mathrm{O}$ objetivo deste artigo é revisar brevemente a origem dos metabólitos secundários das plantas, as principais técnicas e avanços recentes para a produção in vitro de PDMCs e os desafios em torno do uso dessa tecnologia promissora.

Palavras-chave: compostos medicinais derivados de plantas, cultura de células e tecidos in vitro, técnicas, fatores bióticos e abióticos, biofábricas.

\section{Received on March 29, 2019; accepted on June 4, 2019}

\begin{abstract}
Medicinal plants as a source of metabolites used as medicaments

Humans have been using plants for thousands of years as a means for maintaining their health. Medicinal plants continue to be the primary type of medicament used in the world currently, especially in tropical and in
\end{abstract}

economically underdeveloped countries. In the last century, society, in its turn, has advanced in knowledge on chemistry and biology, which allowed the isolation of new molecules from plants, animals, and microorganisms, as well as the development of synthetic molecules, giving rise to the present generation of conventional medicines. However, despite the significant progresses observed in the pharmaceutical field, problems related to many of the conventional medicaments, such as high costs and collateral effects, are present complications of medication overuse.

Antibiotics illustrate well this 
context: they are efficient against infectious diseases and avoid the death of millions in the world every year if used correctly and safely. However, their inappropriate use may lead to different types of bacterial resistance, which is one of the reasons for the current antibiotic crisis, along with the limited development of new molecules (Martens \& Demains, 2017).

Based on these constraints, the use of medicinal plants is becoming increasingly important, especially in the last decade. Part of this is due to a return to the principles of dealing with some diseases, while, in another direction, the current capacity of science to prove both the efficacy and the safety of plants used as a medication, also plays a role (Hoareau \& Silva, 1999; Petrovska, 2012). Among their advantages over conventional drugs, medicinal plants make highly complex organic biosynthesized molecules available naturally, reducing the costs of using them as medicaments, with fewer collateral effects.

It is worth considering also that megadiverse countries, such as Brazil, have important issues to address. For example, the need to prospect plants, animals, and microorganisms' natural molecules and their uses, including their medicinal properties, and how to deal with the vast and unexplored biodiversity in the face of the need to expand other economics activities that may threaten the environment. Part of the strategy for biodiversity management in megadiverse countries might be the use of biodiversity E-infrastructures to meet public demands and to open access to data about species (Canhos et al., 2015).

What is the origin of the PlantDerived Medicinal Compounds (PDMC)?

In this paper, we concentrate only in the secondary metabolites used as medicaments, and we employ the term Plant-Derived Medicinal Compounds (PDMC) to distinguish these from other types of secondary metabolites used for other purposes.

Most PDMC come from the socalled secondary metabolism of plants, whose primary ecological role for the plant is to biosynthesize molecules to increase the plant capacity to adapt to the wild environment, especially in terms of defense and signaling (Wink, 2003). Plant primary metabolism includes essential life mechanisms, such as photosynthesis, respiration, water, and nutrient uptake and assimilation. Plant secondary metabolism, in its turn, uses energy and other molecules generated in the primary metabolism to produce a range of thousands of types of other compounds involved in increasing plant adaptability to different environmental conditions, especially molecules to respond to the biotic and abiotic stresses characteristic from wild environments. Besides, the secondary metabolism allows plants to communicate, at least from a chemical point of view, with animals and microorganisms, opening room to synergistic and antagonistic relationships, with many ecological functions.

Therefore, it is expected that many of the secondary metabolites a plant uses as their defense mechanism against pathogens can also serve as antimicrobial compounds, since they have the capacity to partial or completely inhibit the proliferation of some pathogens. The socalled PDMC arises from the correlation between the plant defense mechanism and the type of action of these secondary metabolites since this type of action can be extended and used as a product to fight diseases also in animals and even humans. It is even very likely that humans had instinctively realized the medicinal potential of plants, by observing other animals' habits of feeding in some specific plants when they were sick or with some disease or pain (Stojanoski, 1999).

It is difficult to say when humans began to use plants as medicines, but it must be associated with the emergence of humans themselves, once plants are the oldest type of medication recorded (Halberstein, 2005). The use of medicinal plants by civilizations is biblical and already reported thousands of years before Christ. Medicinal plants are often related to religious cults and beliefs or even to the popular tradition, which employs many plants to fight infectious diseases, in addition to other uses. Records from 6000 to $3000 \mathrm{BC}$, in Egypt, China, and India showed one of the earliest collections of plant species with pharmacological principles (Ang-Lee et al., 2001). Nevertheless, some authors claim that, much before, Neanderthals already used plants for medicinal purposes, 60 thousand years ago (Shanidar, 1975).

This previous awareness, coupled with up-to-date scientific evidence of the bioactive chemicals present and produced in the plant biomass, along with the safety of using some medicinal plant species, lead to the rediscovery of PDMC as medicaments. Such a revival implied in significant economic growth for the sector, reaching and moving an industry of billions of dollars worldwide, with relevant consequences especially to developing countries, where the access to conventional treatments is limited (Bukar et al., 2016).

It is important to note that medicinal plants may be used in their entirety, fresh or dried and ground, and contain several $\mathrm{PDMC}$ at once. Such characteristics are founding principles of the phytotherapy. On the other hand, most conventional medicinal products, including those containing molecules derived from medicinal plants, in this case, isolated from the whole, contain a single PDMC as a chemical marker of reference. Cinnamon is an illustrative example of these two treatments: while the use of the cinnamon bark as infusion to treat infectious diseases characterizes the use of the medicinal plant; its main secondary metabolite, cinnamaldehyde, which is isolated from the bark, proved to be an efficient antimicrobial agent (Zhang et al., 2015) and can be used as a conventional medicament, similar to other types of synthetic antimicrobials.

Many of the conventional drugs produced by the pharmaceutical industry come from molecules isolated from plants or other living organisms. Approximately $67 \%$ of anti-cancer drugs have molecules isolated or primarily synthesized by plants or animals in their composition (NCI-NHI, 2007). Many of them are references in the treatment of cancer and specially used as chemotherapeutics. That is the case of Taxol (Paclitaxel), a PDMC 
obtained from the Taxus brevifolia bark and currently on the FDA-approved list of cancer treatments. Unfortunately, this use placed the species in danger due to the drastic reduction of its natural populations in the wild: the need for the bark to obtain Taxol led to a drastic reduction in $T$. brevifolia populations (Thomas, 2013, Weaver, 2014) since the bark removal results in the death of the trees. Other important issues to consider when using medicinal plants are those related to health risks (Smet, 2004) that can be caused, for example, by species misidentification, mistakes in dosage, intoxication, and interaction between plants and other drugs. Finally, we should not overlook environmental matters. Unsustainable exploitation can dangerously reduce natural populations and narrow the genetic basis of the species used as the PDMC source (Cardoso \& Silva, 2013).

In this sense, horticulture can contribute in many ways, from the domestication of wild medicinal plants, increasing plant biomass and PDMC productivity as a way of stimulating its production in a commercial basis, to the use of plants as natural bioreactors, thus indirectly mitigating the unsustainable exploitation of natural resources. The horticultural science can provide methods to produce native and exotic PDMC-source plants in agroecosystems, using some techniques proved efficient in regular horticulture, i.e., for food productions, such as, for example, physical and chemical soil preparation, fertilization and other specific treatments.

In Brazil, different programs to improve the production of medicinal plants have been stimulated by different agents of the government or industry, in which the farmer-company-government partnership has been successful in increasing the production of some medicinal plants by both extending the growing area and using adequate technology to each specific crop. As far as the government is concerned, it is worth mentioning three initiatives: (i) the National Policy for Medicinal Plants and Phytotherapy (Brazil, 2006), also launched to improve the research involving medicinal plants and to value and appraise the extensive and diverse traditional knowledge related to their uses; (ii) the presence of some medicinal plants in the Brazilian National Registry of Medicaments (RENAME) and; (iii) the list of 71 species published by the Brazilian Ministry of Health with the objective of improving the knowledge and the bulk of technical-scientific information related to these species, aiming at their registration and further use as medication.

Despite the contribution medicinal plants can give to individuals and health systems, their use as drugs, without recommended dosages and professional care, can result in unsuccessful treatment and undesirable collateral effects. All medicinal plants have one or more PDMCs that act in human metabolism. Thus, it is necessary to control the medicinal compound (drug) dosages and frequency for achieving positive and safety results in the treatment. The Brazilian Policy of Medicinal Plants and Phytotherapy also recommends capacity strengthening for health professionals aiming at improving the accuracy of prescriptions and the quality of patient orientation when using medicinal plants. Thus, it is expected that medicinal plants could be employed more often in public health, with easier and cheaper access than conventional drugs. The low number of studies investigating the actual action mechanism of medicinal plants on human disorders currently limits their broader use in public health systems. More evidence warranting the safety use of medicinal plants as drugs, with robust scientific background, would contribute to improving their use in health systems.

From a business point of view, we highlight three main examples of improved medicinal plant chains in Brazil: Itaipu Binacional and its encouragement to the regional community towards sustainable production, commercialization and use of medicinal plants; the Centro Pluridisciplinar de Pesquisas Químicas, Biológicas e Agrícola (Multidisciplinary Center for Chemical, Biological and Agricultural Research, University of Campinas) (CPQBA/UNICAMP), which preserves collections of different medicinal plants and carries researches on breeding, physiology, phytochemistry, propagation, and crop technology involving medicinal plants, and; the company Centroflora that has partnerships with local growers aiming at stimulating the growth and production of some species containing PDMCs the industry is interest in, for isolating and stabilizing these components which are later sold to the pharmaceutical industries. The comprehensive structuration of these chains is crucial to allow farmers to invest resources in producing crops with an exceptional economic value, assuring sales to the industry, which, in its turn, needs a stable flow of high-quality plant raw matter to extract PDMCs.

Pests and diseases are one of the significant challenges currently faced by those growing medicinal plants in Brazil. There is a general lack of pesticides registered for medicinal plants and the need of using unregistered ones often results in undesired contamination of extracted or isolated PDMC (Zuin \& Vilegas, 2000, Gerth et al., 2007, Tripathi et al., 2015). The methods of PDMC preparation, purification, and isolation also concentrate some pesticides and other toxic undesirable molecules. The sensitivity of most PDMC to environmental factors and growing techniques (Gobbo-Neto \& Lopes, 2007) also challenges the chain, once it makes it very difficult to standardize lots with a minimum concentration of the target PDMC to warranty the efficiency of the treatment. Other factors that influence PDMC production are the genotype and the plant organ used and the life cycle: in some tree species, the PDMC is available only in the adult stage, after a long growth period.

These factors influence significantly the biosynthesis of the secondary metabolites that result in the PDMCs of interest, which can belong to three main classes, basically: the terpenes, the phenolic compounds, and the alkaloids. Each class of secondary metabolites is a result of a complex network of precursors, enzymes and co-factors, some of them leading to specific PDMCs. 


\section{The concept of PDMC in vitro production}

In vitro culture involves the production of new cells, tissues, and organs derived exclusively from the mitotic cell division, thus generating cloned cells, tissues, and individuals, namely, with the same genetics of the mother plant. The use of in vitro techniques to produce secondary metabolites, especially PDMCs, has as main advantages: less environmental interference due to the controlled conditions in in vitro growing rooms; possibility of more control over the PDMC production by developing stepby-step protocols to accelerate fresh biomass accumulation and increase PDMC concentration in the tissues; the season-independent staggered production of PDMCs; PDMC production under sterile conditions and with very few risks of contamination by undesired toxic compounds.

PDMC in vitro production consists of growing explants from the target medicinal plant employing plant cell and tissue culture techniques. Explants are surface sterilized and inoculated on in vitro conditions, using a previously formulated culture medium, and cultivated for different phases under controlled environmental conditions. Culture media contain organo-mineral formulated solutions to nurture the tissues; sugars, such as sucrose, to act as the energy source to a system (in vitro conditions) in which light conditions and low $\mathrm{CO}_{2}$ concentrations severely limit photosynthesis (photomyxotrophyc conditions); plant growth regulators, used to control tissue development and to stimulate the increase of plant biomass and PDMC contents; as well as other additional products such as amino acids, vitamins, activated charcoal, antioxidants, and specific substances used for each individualized protocol.

In this context, explants such as shoot tips containing the apical stem meristem, leaf segments, and others, are surface sterilized (asepsis) to reduce the occurrence of microorganisms in plant tissues using alcohol 70\% or sodium hypochlorite. Following, these explants are inoculated into a specific culture medium for the establishment of the in vitro culture, i.e., the development of shoot meristems into callus (undifferentiated tissue), plantlets (aerial part + roots), shoots (aerial part) or only roots in vitro. Some explants, such as leaf segments, have an additional in vitro phase called organogenesis, in which specialized cells resume their capacity of cell division and develop callus (indirect organogenesis) or buds and shoots directly from the original tissue (direct organogenesis).

After the successful establishment of the in vitro culture without microorganism contamination, next phases consist of multiplication of cells, tissues, shoots, and roots. These phases are critical to the economic viability of the process, mainly because the more cells and tissues are produced, the higher the yield of the target PDMC.

The remaining stages of micropropagation are rooting and acclimatization of the in vitro plantlets under greenhouse conditions, but these are performed only to produce largescale clonal plantlets, including some medicinal plants. The whole process, except for acclimatization, is carried out under in vitro cultivated conditions, in glass or plastic bottles sealed to prevent contamination, keeping control of temperature, light (quality and intensity) and photoperiod.

The in vitro cultivation of PDMC plant species can help the production of medicinal plants in several ways. Here, we highlight the following techniques: 1) large scale propagation of clonal plantlets with high genetic and sanitary quality and high PDMC concentration and the propagation of species which are difficult to multiply by conventional methods, such as those with long growth cycle or systemic phytosanitary problems, for example, the occurrence of viruses and bacteria that are typically potentiated by conventional vegetative propagation; 2) the use of elicitors (biotic or abiotic treatments applied to the biomass to stimulate the production of secondary metabolites) to stimulate tissues usually obtained under in vitro conditions to produce target PDMCs, followed by the multiplication of these tissues, and; 3 ) genetic transformation of species used as bioreactors to induce
PDMC development in specific tissues, aiming at improving the production efficiency of biomass, cells and, thus, PDMCs from rare species or species with difficult cultivation or very long cycle, or even of PDMCs of interest, but produced at low concentration in the original species.

The $1^{\text {st }}$ technique can contribute to the production of herbal medicines and conventional products that use PDMCs extracted from medicinal plants. The in vitro cloning techniques accelerate the production of clonal plantlets from those genotypes performing better on both agronomic aspects and aspects related to the medicinal characteristics of interest. Although the $2^{\text {nd }}$ and $3^{\text {rd }}$ techniques may also result in the production of herbal medicines, their most significant application is the in vitro production of PDMCs of higher commercial value, also due to the higher costs involved in the use of these techniques (Cardoso et $a l ., 2018$ ). In the case of technique 3 , the inherent contained conditions of in vitro systems circumvent the issues related to the release of transgenic medicinal plants for ex vitro cultivation, which involves complex regulatory processes and could also result in several inquiries from consumers, mainly for some food species (Cardoso, 2018). In this case, in vitro transgenic live tissues will be meant only to produce in vitro biomass (transgenic), aiming at the extraction of the purified chemical PDMC (with non-transgenic residues).

An example of the later would be the development of transgenic tobacco lines with the biosynthetic capacity to produce rare PDMCs, such as the alkaloids Vincristine and Vinblastine. These alkaloids are extracted originally from Catharantus roseus and used for producing vincristine and vinblastine sulfates, two chemotherapeutic agents widely used to treat some types of cancer. In this case, callus cells from transgenic tobacco would serve as a bioreactor for the in vitro production of the chemicals. These fast-multiplication cells would allow increasing the PMDC production exponentially. Tobacco is the choice because it is an excellent model for genetic transformation and allow controlling the development of in vitro 
tissues. Transgenic tobacco could also be used to produce, in addition to PDMCs, different biopharmaceuticals, such as vaccines, hormones, and antibodies (Goldstein \& Thomas, 2004).

The $2^{\text {nd }}$ and the $3^{\text {rd }}$ techniques have the most significant bulk of studies involving PDMC production from tissues, performed in several species that biosynthesize target metabolites. This momentum comes from the advantages of producing PDMCs using these techniques in comparison to producing plants using technique 1, which requires a long multiphase protocol, including genotype choice, asepsis, in vitro inoculation and regeneration, multiplication of callus, cells, roots and/or shoots, followed by elicitation, extraction, and quantification of the PDMC of interest.

\section{Main factors affecting PDMC production}

The genotype has unquestionable direct effects over the production of plant biomass and PDMCs. The prospection of genotypes with high PDMC contents and the establishment of breeding programs are both excellent strategies to increase the productivity of these compounds in domesticated and cultivated medicinal plants. As an example of these possibilities, in jaborandi (Pilocarpus microphyllus) the pilocarpine content ranges from 16.3 to $235.9 \mu \mathrm{g} \mathrm{g} \mathrm{g}^{-1}$ in dry weight (Sandhu et al., 2006), a difference of 14.5 times in the native pilocarpine content. Nevertheless, research prospecting genotypes of medicinal plants with high PDMC contents is limited and has been carried out mainly by private companies or growers, limiting public access to more promising genetic material from the economic point of view.

The use of genotypes with high natural PDMC contents is an essential condition to the success of the in vitro production due to the higher costs of the system compared to other conventional techniques. Besides, as in vitro cultivation is based on mitoses (clonal origin), more efficient genotypes will result in significantly higher PDMC concentrations in the plant or tissues grown in vitro. However, growing conditions, especially in the field, can induce significant variations in the production of plant mass and PDMC contents, even in high-yielding genotypes (Vaz et al., 2006). Therefore, it is essential that the conditions that provide the best genotype-environment relation are known, even for in vitro systems. In field conditions, both endogenous factors, to mention genotype, plant organ and age, circadian clock; and exogenous factors, such as photoperiod, light intensity and wavelength, temperature, water availability, cropping system, soil type, and atmospheric composition, can individually or jointly affect both the composition and the concentration of a single or different PDMCs (Gobbo-Neto \& Lopes, 2007; Cui et al., 2011).

These same factors can also influence the PDMC in vitro production. For example, Kapoor et al. (2018) reported the influence of light quality on the production of accumulated biomass, growth rate, and concentration of the phenolic compound Salidroside in Rhodiola imbricata. Kapoor et al. (2018) found the highest callus growth index (2.97) in red-light and the highest concentration of the total phenolic compound and Salidroside using blue light, in 21-day callus. As they observed, in vitro systems are established using protocols based mainly in culture medium and environmental conditions adjusted to the different phases of the in vitro growth. If the highest plant in vitro growth was obtained using white light, but the PDMC biosynthesis required blue light, a protocol should comprise at least two stages, one for plant tissue growth and another for increasing the PDMC concentration in those tissues. In other words, if the protocol uses callus as the primary source of cells for the PDMC in vitro production, callus proliferation should be carried out under white light, particularly in the exponential phase of cell or tissue growth, to accelerate and increase the biomass. Under the stationary growth phase, these tissues should be placed under blue light to increase the production of the target PDMC in each of the cells obtained in the previous phase (Figure 1). Other strategies can be designed to improve the efficiency, such as combining blue/white light in adequate rates for cell proliferation and PDMC stimulation. Similar tactics should be used for other factors, combining the ideal requirements for plant tissues and PDMC production on in vitro conditions.

In vitro environments offer the possibility of controlling the conditions

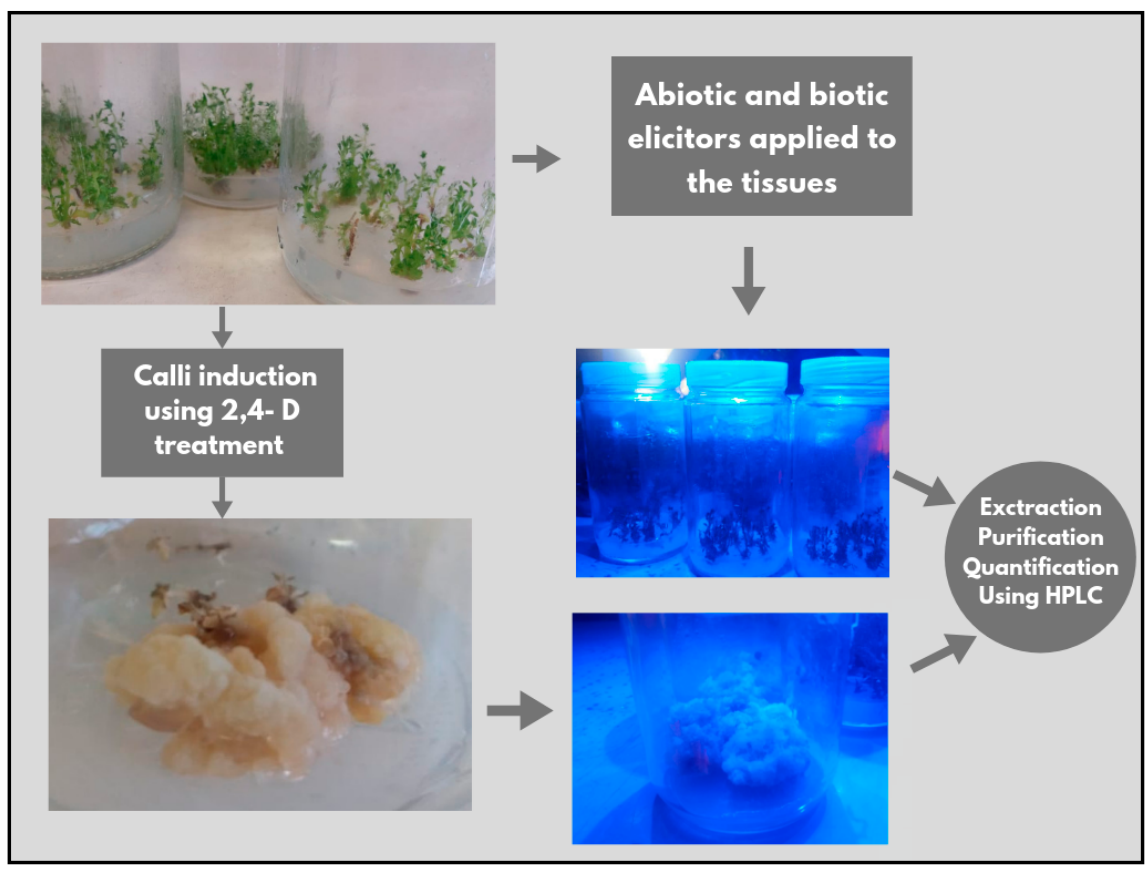

Figure 1. In vitro culture of Phyllanthus amarus established to produce the PDMCs phyllanthin and hypophyllanthin through shoot and callus. Araras, UFSCar, 2019. 
that optimize the production of metabolites, independent of the time of the year and under aseptic conditions, which are both significant advantages of the system. On the other hand, the main disadvantage lies in the high production cost, which should be compensated by using the area and time provided by the system as intensely as possible. The main factors used for calculating the PDMC yield on in vitro environments should be fresh or dry mass and the PDMC concentration on them, the area used by the cultivation bottle or bioreactor (liquid media), and the time spent to obtain a PDMC production cycle. Therefore, we can summarize that the PDMC productivity can be calculated by different points of view and under different systems of cultivation. Other factors, such as the volume of culture medium, could also be used in this formula. However, culture media usually represents less than $5 \%$ of the total cost. Thus, considering the in vitro culture system, all factors influencing the fresh/dry biomass production, the PDMC biosynthesis, the area used by the flasks, and the culture cycle is crucial to determine the efficiency and productivity of PDMC under in vitro conditions.

The area used by the culture bottles varies according to the type and size of bottles, the efficiency of biomass accumulation in the protocols, and the system used. Conventional systems use semi-solid medium, containing agar, or liquid medium, under intermittent agitation, or even in culture under temporary immersion bioreactors (TIB). The use of the TIB has resulted in increases in the accumulation of plant biomass with good PDMC concentration compared to other conventional techniques using agar-based protocols (Gerth et al., 2007; Thakore et al., 2017).

Abiotic factors, such as temperature, light (intensity, photoperiod, and wavelength), relative humidity, and the atmospheric composition inside the bottle strongly influence the fresh and dry biomass accumulation, the PDMC concentration in the biomass and the cultivation period, which are, in their turn, also biological- dependent characteristics. The culture medium and its components, such as water availability and water potential of the culture medium, macro and micronutrients, carbohydrates, vitamins and amino acids, and phytoregulators of different classes, such as auxins, cytokinins (Grzegorczyk-Karolak et al., 2015) gibberellins, jasmonates, and salicylates (Ali et al., 2015) also influence these characteristics.

Other factors of influence are the type, intensity, and period of exposition of tissues to elicitors, which are used to stimulate the biosynthesis and increase in the PDMC concentration at the end of the growth cycle, or the accumulation of plant biomass (Siddiqui et al., 2013). Elicitors are chemical substances applied to the culture medium, ionizing radiation or other physical factors applied to the cells and tissues (Naik \& Al-Khairy, 2016), or even co-culture of plant tissues with specific microorganisms (Tonk et al., 2016) or application of environmental stresses, such as high or low temperatures for a given period. Among the chemical substances applied to the culture medium, there are some phytoregulators, such as the salicylic and jasmonic acids (Sharma et al., 2015), chitosan (Ferri \& Tassoni, 2011), microorganisms extracts (Maqsood \& Abdul, 2017), in addition to other new generation molecules (RamirezEstrada et al. 2016). Among physical factors, ultraviolet radiation has been used frequently and has effects over different active principles produced in vitro (Klein et al., 2018).

The co-cultivation of plant cells with microorganisms has been used to elicitate some PDMCs. In Catharanthus roseus, the use of Aspergillus flavus in co-cultivation with plant tissues resulted in increases of 7.88 and $15.5 \%$ in the vinblastine and vincristine concentration, respectively, compared to non-elicited control tissues (Tonk et al., 2016). It is very probable that the activation of the synthesis of some secondary metabolites in response to microorganisms is associated with the biological function of these PDMCs in pathogen control. Ludwig-Müller (2015) reported the induction of secondary metabolism in plants also by endophyte microorganisms. However, the co-cultivation of plant tissues with microorganisms could also result in increases in the PDMC production costs because their use involves two types of organisms and, consequently, two different protocols, followed by the co-cultivation period. Also, the microorganism used for co-cultivation may produce toxic components and increase risks of contamination of plant cells.

Therefore, the development of a protocol for the in vitro culture of cells, tissues, and the medicinal plant itself to produce the target PDMC requires an extensive search for the existing knowledge on the species and the PDMC. Based on all previous factors presented by the literature and tested both ex- and in-vitro, including the use of elicitors to increase the biochemical routes to the PDMC, one is more likely to develop successful high-yielding in vitro systems customized for specific plants and target PDMCs.

\section{The main systems used for the in vitro production of secondary metabolites}

In vitro micropropagation, followed by plantlet acclimatization and growth in greenhouse or in the field, is a promising strategy to produce plant secondary metabolites, especially in rare or endangered species, in those difficult to propagate (Kapoor et al., 2018) or of slow growth (Cardoso \& Silva, 2013), and in species vulnerable to recurrent phytosanitary problems, such as those of vegetative propagation. In the later, the techniques used to produce virus-free plants may be helpful also to increase both plant biomass productivity and PDMC contents, as observed in Allium sativum. In vitro techniques also allow for and accelerate the large-scale propagation of selected genotypes with high PDMC contents, either native or developed in breeding programs. In addition to conventional micropropagation, PDMC can be produced in vitro by callus induction and growth, cell culture, shoot proliferation, and the protocol of inducing hairy roots using transgenic techniques.

Shoot culture and proliferation

Shoot proliferation is similar to 
conventional micropropagation. It involves the inoculation of surfacesterilized tissues in culture medium for shoot regeneration, followed by inducing shoot proliferation, usually by adding cytokinin as the main phytoregulator to the culture medium. After some cycles of shoot proliferation and in vitro mass accumulation, an elicitor is applied to increase the PDMC concentration in the tissues. Plantlets are then used to extract, characterize, and quantify PDMCs, instead of being directed to rooting and acclimatization, as it is in conventional micropropagation.

To determine and quantify the main secondary metabolites produced by shoot culture in Scutellaria alpine, Grzegorczyk-Karolak et al. (2015) cultivated $0.5 \mathrm{~cm}$-long shoot tips in different cytokinin types and concentrations. Shoot tips came from surfaced sterilized seeds, germinated in vitro on MS medium. These authors found that, while 6-Benzylaminopurine $(2-4 \mu \mathrm{M})$ resulted in the highest shoot proliferation and biomass accumulation, cytokinin type and concentration, as well cytokinin combination with the auxin Indole Acetic Acid, influenced both the composition and concentration of secondary metabolites in shoots. Regarding the use of elicitors, Sharma et al. (2015) reported that maximum bacoside contents on in vitro shoot cultures $\left(8.73 \mathrm{mg} \mathrm{g}^{-1}\right.$ dry weight) of Bacopa monnieri resulted from using $45 \mathrm{mg} \mathrm{L}^{-1}$ of $\mathrm{CuSO}_{4}$ in the culture medium, combined with a shoot elicitor incubation period of 6 to 9 days. They also found that both jasmonic acid at $1.0 \mathrm{mg} \mathrm{L}^{-1}$ and salicylic acid at $50 \mu \mathrm{M}$, with 6- to 9-day incubation, resulted in increased bacoside concentration, 8.46 and $8.14 \mathrm{mg} \mathrm{g}^{-1}$ dry weight, respectively, compared to control conditions without elicitor (6.41 $\mathrm{mg} \mathrm{g}^{-1}$ dry weight).

\section{Callus and cell suspension culture}

Callus induction and multiplication have been extensively used in PDMC in vitro production. It is an efficient approach to produce PDMCs in large scale when compared to other techniques, mainly because the in vitro callus induction is a straightforward and rapid system of cell multiplication (Kapoor et al., 2018). Besides, the factors that induce callogenesis are well studied (Ahmad et al., 2016), highly consistent, and used commercially already for some decades in tissue culture for other applications.

The use of callus culture is also associated with the competence of many plant cells and tissues, from different plant organs, to produce calli in response to a simple stimulus, generally with the application of auxins, especially 2,4-Dichlorophenolic Acid, and/or cytokinin phytoregulators in the culture medium (Ahmad et al., 2016). This great advantage comes from the fact that most callus cells acquire a continuous growth capacity if the conditions of the culture medium remain favorable. Therefore, cells maintain cycles of constant division, extending significantly a period known as the growth exponential phase, which is followed by a stationary phase with reduced growth. The ability to maintain these cells in a nondifferentiating condition makes the process more manageable from the biological point of view and results in higher mass production per unit of time and area when compared to other regeneration processes of tissues, organs or individuals, generally more complex and more expensive.

In Stevia rebaudiana, leaf-piece explants were surface-sterilized and inoculated in MS culture medium, containing $2.0 \mathrm{mg} \mathrm{L}^{-1}$ of 6-Benzyladenine (BA) and $2.0 \mathrm{mg} \mathrm{L}^{-1} 2,4-\mathrm{D}$ to induce callus formation (Ahmad et al., 2016). These authors tested the influence of the quality of the light on callus production.

The genus Phyllanthus has important PDMCs, especially the alkaloids phyllantine and hypophyllanthin (Lee et al., 2016). Seeds of a genotype of Phyllanthus amarus with high concentrations of these alkaloids, selected by the CPQBA/UNICAMP (Vaz et al., 2006), were previously germinated in vitro using the MS culture medium at half-strength. Derived $1-\mathrm{cm}$ long micro-cuttings were transferred for callus induction into similar medium, adding $0.5 \mathrm{mg} \mathrm{L}^{-1} 2,4-\mathrm{D}$. The induced calli were kept in the same medium for proliferation, in the dark, with cycles of transference of 20-30 days after inoculation (unpublished data, Figure
1). Various elicitors will be used to test the capacity of the callus cells to produce phyllantine and hypophyllanthin. The callus obtained in vitro also can be used also for establishing new suspensions of cell cultures. Thus, new cell cultures become a regular additional phase of the callus culture, in which the friable type of callus starts a new cell culture in liquid media.

In Hypericum perforatum, cell cultures were induced in liquid MS medium containing $1.0 \mathrm{mg} \mathrm{L}^{-1}$ 2,4-D and $0.2 \mathrm{mg} \mathrm{L}^{-1} \mathrm{BA}$, obtained from a previous induced friable callus, using the same culture medium, but with agar. The friable callus was essential for successfully establishing the cell suspension. Only stem explants resulted in this type of callus, while leaf and calyx tissues originated hard and green non-friable calli. After transferring the friable calli to liquid media, the flasks were placed on a rotary shaker and transferred to a new culture medium every 20 days. These authors reported that maximum fresh $\left(\equiv 200 \mathrm{~g} \mathrm{~L}^{-1}\right.$ culture medium) and dry ( $\equiv 7-8 \mathrm{~g} \mathrm{~L}^{-1}$ culture medium) weight were obtained after 20-25 days, when also the highest contents of flavonoid accumulation ( $\equiv 15-16 \mathrm{mg} \mathrm{g}^{-1}$ dry weight) were found in tissues. Wang et al. (2015), in their turn, reported that the use of methyl jasmonate and salicylic acid as elicitors resulted in flavonoid increases in cell suspension cultures, 2.1 and 1.5 times higher than the control treatment.

Hairy root cultures are those in which the genetic transformation mediated by the bacteria Agrobacterium rhizogenes is used to induce and obtain hairy-root lines (Chen et al., 2018) in tissues already established in vitro. Hairy-root lines are important sources of stable cells specialized in the production of useful PDMCs in amounts higher than those obtained from cell cultures (Sujatha et al., 2013), in several species.

Sujatha et al. (2013) used four strains of Agrobacterium rhizogenes to transform shoot tips, leaves, and nodes of Artemisia vulgaris, and observed that the A4GUS strain combined with leaf explants resulted in the highest transformation response, with $92.6 \%$ of transformation success. From all 
transgenic hairy-root strains obtained from leaf explants, Sujatha et al. (2013) selected AV1 and AV2 because they grew better, with higher root elongation, ramification, and biomass accumulation. The cultivation of these transgenic hairy-root strains resulted in higher growth rate (9x), types (87), and concentration $(0.51 \%)$ of essential oils, compared to non-transformed roots ( $7 \mathrm{x}, 77$, and $0.43 \%$, respectively). The hairy-root induction, combined with the temporary bioreactor immersion system, can also improve the PDMC productivity of hairy-roots. Aiming the production of Ajmalicine from Catharanthus roseus, Thakore et al. (2017) observed the effect of days of cultivation, sucrose concentration in the culture medium, inoculum size, photoperiod, type of the bioreactor system, and aeration volume on the growth of hairy roots and concentration of Ajmalicine, and concluded that the bubble gum bioreactor combined with polyurethane support improved significantly the hairy-root dry biomass (15.4 times in 30-day cultivation) and the concentration of Ajmalicine $\left(34 \mathrm{mg} \mathrm{L}^{-1}\right)$, when compared to conventional rotating drum system of in vitro cultivation (3.4 times, and $4.6 \mathrm{mg} \mathrm{L}^{-1}$ ).

Most of the authors who compared hairy root cultures with cultures of cell, callus, and shoots to PDMC production observed many advantages for hairy roots and concluded that, overall, the most important are the genetic stability of hairy-root cultures, their long-lasting capacity to keep cell viability, and their good capacity to produce different PDMCs in high concentration (Sujatha et al., 2013; Thiruvengadam et al., 2016; Thakore et al., 2017). Therefore, the hairy-root technique is definitely an appropriate and viable choice to the large-scale PDMC in vitro production.

\section{Challenges and conclusions about PDMC in vitro production}

Among the limitations for the in vitro production of secondary metabolites, the low biomass yield, resulting in reduced PDMC production on these conditions, stands out. Besides, the higher production costs, due to the controlled environmental conditions and need of specialized labor (Cardoso et al.,
2018), when compared to field grown medicinal plants, also contributes to the low number of large-scale, profitable systems to produce PDMC in vitro we currently observe. Most of the in vitro techniques are still more appropriate to research and to understand the factors affecting the production of different PDMCs in several medicinal plant species. Like other plant tissue culture applications, large-scale PDMC in vitro production can be useful first for high-value and rare target PDMCs. The increase in the knowledge about the biochemical routes and genes that control the complex routes resulting in PDMCs, associated with advances in plant synthetic biology, specially related to metabolic engineering, will result in significant improvements in genetic transformation or organism reconstruction techniques, similar to some already experienced in the production of secondary metabolites from microorganisms (Wu \& Hong, 2013).

Another limitation is the high cost for extraction, purification, and analysis of PDMCs obtained in vitro. Most of the methods involve the use of HighPerformance Liquid Chromatography (HPLC) or ultra HPLCs for analysis, i.e., a few hundred dollars per analysis. Nevertheless, these costs may be diluted in large-scale systems and worth in case of high-value PDMCs.

Natural products are powerfully re-emerging in the genomic era, and metabolomics and metagenomics are increasingly efficient in identifying new ones (Harvey et al., 2015). In this context, the generation of transgenic plants with high capacity to produce PDMCs opens a new age for the discovery and re-discovery of natural molecules, derived from either plants or plant-microorganism interactions, valuable for medical ends and other purposes. Despite some technical limitations of the current systems for PDMC in vitro production, the highly controlled environment in plant/ cell/callus biofactories, associated with the large capacity of in vitro systems to obtain high-concentrated and contamination-free compounds will constitute a realistic part of the production of different PDMCs. Such systems are among this century's cutting-edge technologies for drug production and development.

\section{ACKNOWLEDGMENTS}

MEBSO and JCC thank FAPESP for the process number 2019/00243-7. JCC thanks $\mathrm{CNPq}$ for the process number 304174/2015-7.

\section{REFERENCES}

AHMAD, N; RAB, A; AHMAD, N. 2016. Lightinduced biochemical variations in secondary metabolite production and antioxidant activity in callus culture of Stevia rebaudiana (Bert.). Journal of Photochemical and Photobiology B: Biology 154: 51-56.

ALI, M; ABBASI, BH; ALI GS. 2015. Elicitation and antioxidant secondary metabolites with jasmonates and gibberellic acid in cell suspension cultures of Artemisia absinthium L. Plant Cell Tissue and Organ Culture 120: 1099-1106.

ANG-LEE, MK; MOSS, J; YUAN, CS. 2001. Herbal medicines and perioperative care. JAMA 286: 208-216

BRAZIL (Ministério da Saúde). 2006. Politica Nacional de Plantas Medicinais e Fitoterápicos. 60 p. Available at http:// bvsms.saude.gov.br/bvs/publicacoes/politica nacional_fitoterapicos.pdf, Accessed March 19, 2019.

BUKAR, BB; DAYOM, DW; UGURU, MO. 2016. The growing economic importance of medicinal plants and the need for developing countries to harness from it: A mini review. IOSR Journal of Pharmacology 6: 2250-3013.

CANHOS, DAL; SOUSA-BAENA, MS; SOUZA, S; MAIA, LC; STEHMANN, JR; CANHOS, VP. 2015. The importance of biodiversity E-infrastructures for megadiverse countries. PLoS Biology 13: e1002204. Available at https://doi.org/10.1371/journal.pbio.1002204.

CARDOSO, JC. 2018. Nonfood GM crops in tropical regions: a reasonable way to promote the technology for increased agricultural sustainability. Global Challenges 2: 1800010.

CARDOSO, JC; SHENG GERALD, LT; SILVA, JAT. 2018. Micropropagation in the twentyfirst century. In: LOYOLA-VARGAS, V, OCHOA-ALEJO, N (org). Methods in molecular biology. $4^{\text {th }}$ ed. New York: Springer. 1815: 17-46.

CARDoso, JC; SILVA, JAT. 2013. Micropropagation of Zeyheria montana Mart. (Bignoniaceae), an endangered endemic medicinal species from the Brazilian cerrado biome. In vitro Cellular \& Developmental Biology-Plant 49: 710-716.

CHEN, L; CAI, Y; LIU, X. 2018. Soybean hairy roots produced in vitro by Agrobacterium 
rhizogenes-mediated transformation. Crop Journal 6: 162-171.

CUI, XH; MURTHY, HN; JIN, YX; YIM, YH; KIM, JY; PAEK, KY. 2011. Production of adventitious root biomass and secondary metabolites of Hypericum perforatum L. in a balloon type airlift reactor. Bioresource Technology 102: 10072-10079.

FERRI, M; TASSONI, A. 2011. Chitosan as elicitor of health beneficial secondary metabolites in in vitro plant cell cultures. In: MACKAY, RG; TAIT, JM (eds). Handbook of Chitosan Research and Applications. Chapter 22: 389-413

GERTH, A; SCHMIDT, D; WILKEN, D. 2007. The production of plant secondary metabolites using bioreactors. Acta Horticulturae 764: 95-104.

GOBBO-NETO, L; LOPES, NP. 2007. Plantas medicinais: fatores de influência no conteúdo de metabólitos secundários. Quimica Nova 30: 374-381.

GOLDSTEIN, DA; THOMAS, JA. 2004. Biopharmaceuticals derived from genetically modified plants. QJM: International Journal of Medicine 97: 705-716.

GRZEGORCZYK-KAROLAK, I; KUZMA, L; WISOKINSKA, H. 2015. The effect of cytokinins on shoot proliferation, secondary metabolite production and antioxidant potential in shoot cultures of Scuttelaria alpina. Plant Cell Tissue and Organ Culture 122: 699-708.

HALBERSTEIN, RA. 2005. Medicinal plants: historical and cross-cultural usage patterns. Annals of Epidemiology 15: 686-699.

HARVEY, L; EDRADA-EBEL, R; QUINN, RJ. 2015. The re-emergence of natural products for drug discovery in genomic era. Nature Review 14: 111-12.

HOAREAU, L; SILVA, EJ. 1999. Medicinal plants: a re-emerging health AID. Electronic Journal of Biotechnology 2: 56-70.

KAPOOR, S; RAGHUVANSHI, R; BHARDWAJ, P; SOOD, H; SAXENA, S; CHAURASIA, OP. 2018. Influence of light quality on growth, secondary metabolites production and antioxidant activity in callus culture of Rhodiola imbricata. Journal of Photochemical and Photobiology B: Biology 183: 258-265.

KLEIN, FRS; REIS, A; KLEINOWSKI, RT; TELLES, RT; AMARANTE, L; PETERS, JA; BRAGA, EJB. 2018. UV-B radiation as an elicitor of secondary metabolite production in plants of the genus Alternanthera. Acta Botanica Brasilica 32: 615-623.

LEE, NYS; KHOO, WKS; ADNAN, MA; MAHALINGAM, TP; FERNANDEZ, AR; JEEVARATNAM, K. 2016. The pharmacological potential of Phyllanthus niruri. Journal of Pharmacy and Pharmacology 68: 953-969.

LUDWIG-MÜLLER, J. 2015. Plants and endophytes: equal partners in secondary metabolite production? Biotechnology Letters 37: 1325-1334.

MAQSOOD, M; ABDUL, M. 2017. Yeast extract elicitation increases viblastine and vincristine yield in protoplast derived tissues and plantlets in Catharantus roseus. Brazilian Journal of Pharmacognosy 27: 549-556.

MARTENS, E; DEMAIN, AL. 2017. The antibiotic resistance crisis, with a focus on United States. Journal of Antibiotics 70: 520-526.

NAIK, PM; AL-KHAYRI, JM. 2016. Abiotic and biotic elicitors-role in secondary metabolites production through in vitro culture of medicinal plants. 10: 247-277. Available at http://dx.doi. org $/ 10.5772 / 61442$.

NCI-NIH (National Cancer Institute - National Health Institute). From the ends of the earth, the search for a cure. NCI Cancer Bulletin 4: 6. Available at https://wayback.archive-it.org/ org-317/20141006122858/http://www.cancer. gov/ncicancerbulletin/archive/2007/112007. pdf, Accessed January 21, 2019.

PETROVSKA, BB. 2012. Historical review of medicinal plants' usage. Pharmacognosy Review 6: 1-5.

RAMIREZ-ESTRADA, K; VIDAL LIMON, H; HIDALGO, D; MOYANO, E; GOLENIOWSKI, M; CUSIDÓ, RM; PALAZON, J. 2016. Elicitation, an effective strategy for the biotechnological production of bioactive high-added value compounds in plant cell factories. Molecules 21: 182. doi: 10.3390/molecules 21020182 .

SANDHU, SS; ABREU, IN; COLOMBO, CA; MAZAFERRA, P. 2006. Pilocarpine content and molecular diversity in jaborandi. Scientia Agraria 63: 478-482.

SHANIDAR, SR. 1975. A Neanderthal flower burial in Northern Iraq. Science 190: 880-881.

SHARMA, M; AHUJA, A; GUPTA, R; MALLUBHOTLA, S. 2015. Enhanced bacoside production in shoot cultures of Bacopa monnieri under the influence of abiotic elicitors. Natural Product Research 29: 745-749.

SIDDIQUI, ZH; MUJIB, A; ASLAM, J. 2013. In vitro production of secondary metabolites using elicitor in Catharanthus roseus: a case study. In: HAKEEM, KR; AHMAD, P; OZTURK, M. Crop Improvement 401-419.

SMET, PAGM. 2004. Health risks of herbal remedies: An update. Clinical Pharmarcology and Therapy 76: 18-26.

STOJANOSKI, N. 1999. Development of health culture in Veles and its region from the past to the end of the $20^{\text {th }}$ century. Veles: Society of Science and Art 13-34.

SUJATHA, G; KORAC-ZDRAVKOVIC, S; CALIC, D; FLAMINI, G; KUMARI, BDR. 2013. High-efficiency Agrobacterum rhizogenes-mediated genetic transformation in Artemisia vulgaris: Hairy root production and essential oil analysis. Industrial Crops Production 44: 643-652.

THAKORE, D; SRIVASTAVA, AK; SINHA, AK. 2017. Mass production of Ajmalicine by bioreactor cultivation of hairy roots of Catharanthus roseus. Biochemical Engineering Journal 119: 84-91.

THIRUVENGADAM， M; REKHA，K; CHUNG, IM. 2016. Induction of hairy roots by Agrobacterium rhizogenesis-mediated transformation of spine gourd (Momordica dioica Roxb. Ex. Willd) for the assessment of phenolic compounds and biological activities. Scientia Horticulturae 198: 132-141.

THOMAS, P. 2013. Taxus brevifolia. The IUCN Red List of Threatened Species 2013: e.T34041A2841142. Available at http:// dx.doi.org/10.2305/IUCN.UK.2013-1.RLTS. T34041A2841142.en.

TONK, D; MUJIB, A; MAQSOOD, M; ALI, M; ZAFAR, N. 2016. Aspergillus flavus fungus elicitation improves vincristine and vinblastine yield by augmenting callus biomass growth in Catharanthus roseus. Plant Cell Tissue Organ Culture 126: 291-303.

TRIPATHY, V; BASAK, BB; VARGHESE, TS; SAHA, A. 2015. Residues and contaminants in medicinal herbs - A review. Phytochemical Letters 14: 67-78.

VAZ, APA; SCARANARI, C; BATISTA, LAR; FIGUEIRA, GM; SARTORATTO, A; MAGALHÃES, PM. 2006. Biomassa e composição química de genótipos melhorados de espécies medicinais cultivadas em quatro municípios paulistas. Pesquisa Agropecuária Brasileira 41: 869-872.

WANG, J; QIAN, J; YAO, L; LU, Y. 2015 , Enhanced production of flavonoids by methyl jasmonate elicitation in cell suspension culture of Hypericum perforatum. Bioresources and Bioprocesses 2: 5. DOI 10.1186/s40643-0140033-5.

WEAVER, BA. 2014. How Taxol/paclitaxel kills cancer cells. Molecular Biology of the Cell 25: $2677-2681$.

WINK, M. 2003. Evolution of secondary metabolites from an ecological and molecular phylogenetic perspective. Phytochemistry 64: 3-19.

WU, LZ; HONG, B. 2013. Synthetic biology toward microbial secondary metabolites and pharmaceuticals. Yao Xue Bao 48: 155-160 (in Chinese with abstract in English).

ZHANG, YB; JIANG, PP; LIU, XY; LI, WD. 2015. Mechanism and antibacterial activity of cinnamaldehyde against Escherichia coli and Staphylococcus aureus. Modern Food Science and Technology 31: 31-35.

ZUIN, VG; VILEGAS, JHY. 2000. Pesticides residues in medicinal plants and phytomedicines. Phytotherapy Research 14: 73-88. 